\title{
Activities of daily living independence level for home discharge in stroke patients based on number of caregivers: an analysis of the Japan Rehabilitation Database
}

\author{
Atsushi SATO ${ }^{1}$, Takaaki FuJita ${ }^{2}$ and Yuichi YAмAмото ${ }^{3}$ \\ ${ }^{1)}$ Department of Physical Therapy, Yachiyo Rehabilitation College \\ ${ }^{2)}$ Tohoku Fukushi University \\ ${ }^{3)}$ Northern Fukushima Medical Center
}

\begin{abstract}
Purpose: This study aimed to calculate cut-off values of activities of daily living independence level for stroke patient home discharge based on the number of family caregivers. Method: The subjects comprised 1442 stroke patients (26 hospitals) who were registered of the Japanese Rehabilitation Database. Receiver operating characteristic curves were used to elucidate the BI and FIM ${ }^{\circledR}$ instrument scores necessary for home discharge. Analysis was performed for each subject according to the number of family caregivers, i.e., no caregiver, one person, two persons or more, and overall. Result: The BI cut-off points that discriminated between home discharge and other were $65 / 60$ points overall, $75 / 70$ points in patients with no caregiver, 65/60 points in patients with one caregiver, and 60/55 points in patients with two or more caregivers. The FIM ${ }^{\circledR}$ instrument cut-off points were $90 / 89$ points overall, 101/100 points in patients with no caregiver, 87/86 points in patients with one caregiver, and 87/86 points in patients with two or more caregivers. Conclusion: Our results indicated that home discharge for patients with many caregivers was possible even with low ADL independence levels, and that there was a large difference in cut-off values depending on the presence or absence of one caregiver.
\end{abstract}

Key words: activities of daily living, home discharge, cut-off values, Japan Rehabilitation Database

(Phys Ther Res 20: 23-27, 2017)

\begin{abstract}
$\mathbf{S}_{\mathrm{t}}$ underlying the need for nursing care ${ }^{1,2)}$ Rehabilitation services are frequently provided with the aim of improving the independence level of activities of daily living (ADL) in stroke patients and their chances of returning to home. The Japanese Guidelines for the Management of Stroke pointed out that "when implementing a rehabilitation program, the prediction and use of functional prognosis; duration of hospitalization; and outcomes based on ADL, impairment, patient attributes, comorbidities, and social background as a reference are recommended" ${ }^{3)}$. It is important to predict the
\end{abstract}

Received: November 2, 2016

Accepted: March 8, 2017

Advance Publication by J-STAGE: July 28, 2017

Correspondence to: Atsushi Sato, [Present address] The Database Center of the National University Hospitals, The University of Tokyo Hospital, 7-3-1 Hongo, Bunkyo-ku, Tokyo 113-8655, Japan

\# e-mail: reha_atsushi_pt@yahoo.co.jp

doi: 10.1298/ptr.E9914 discharge destination of a stroke patient for the implementation of effective intervention.

Whether or not a stroke patient can return home is associated with ADL independence level at hospital discharge ${ }^{4-7)}$. Hamaoka et al. ${ }^{8)}$ reported that the cut-off values of the motor and cognition subscales of the FIM ${ }^{\circledR}$ instrument for stroke patient home discharge were 57.5 and 23.5 points, respectively. Sugiura et al. ${ }^{9}$ reported that an FIM $^{\circledR}$ instrument motor subscale score of less than 39 at discharge indicated that home discharge for stroke patients aged over 85 years was difficult. These reports are useful indices for understanding how essential the ADL independence level is for stroke patient home discharge.

Conversely, the presence of family and the number of caregivers are also reportedly associated with stroke patient home discharge $\mathrm{e}^{7,10-12)}$. This means that home discharge of stroke patients depends on the number of family caregivers, even in patients with the same ADL independence level. Therefore, the cut-off values of ADL independence level 


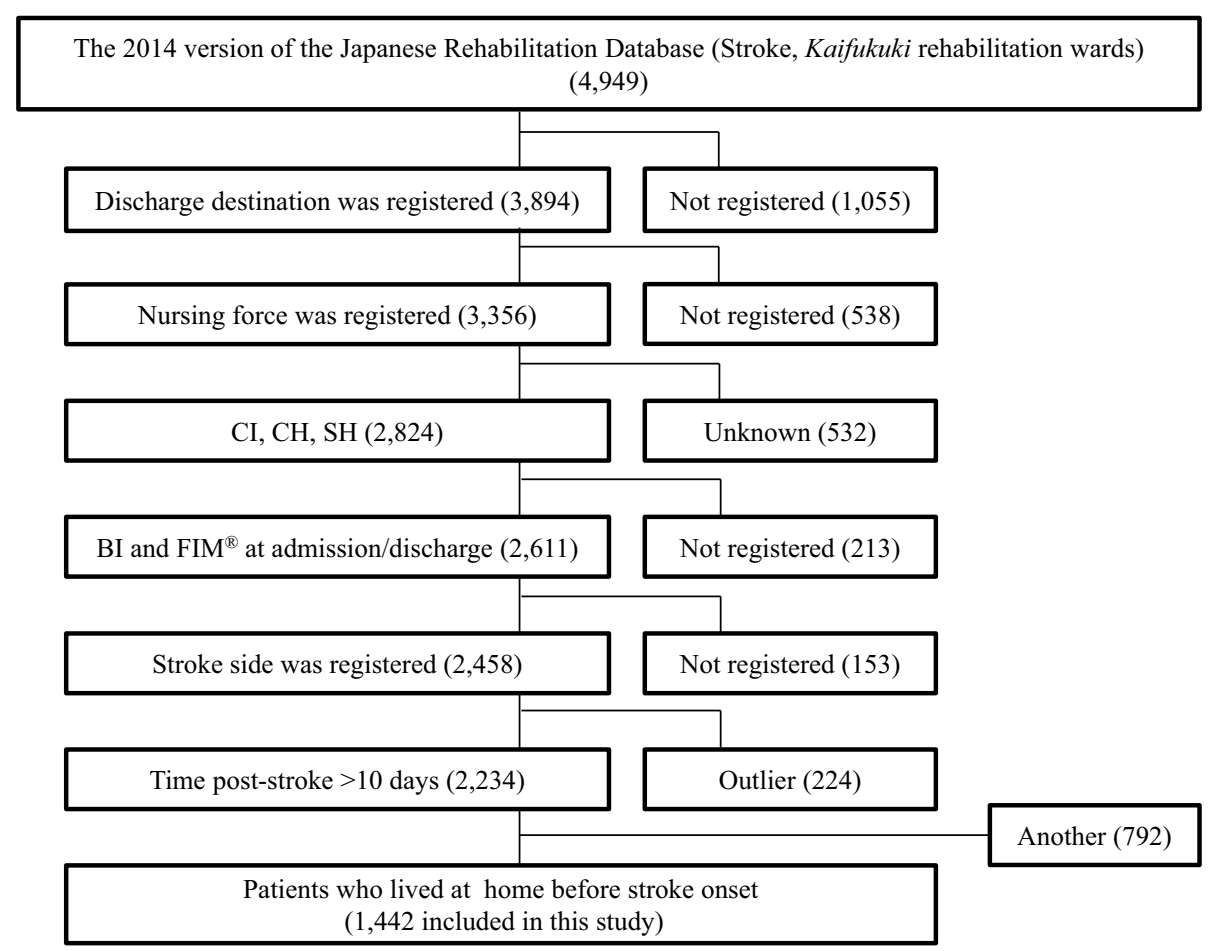

Figure 1. Flow chart of participant selection

$\mathrm{CI}=$ cerebral infarction; $\mathrm{CH}=$ cerebral hemorrhage; $\mathrm{SH}=$ subarachnoid hemorrhage; $\mathrm{BI}=$ Barthel Index; FIM $^{\circledR}=$ FIM $^{\circledR}$ instrument

for stroke patient home discharge should be calculated based on the number of family caregivers. However, to the best of our knowledge, no reports have calculated the ADL independence level necessary for stroke patient home discharge based on the number of family caregivers. Clarification of the ADL independence level for home discharge based on the number of family caregivers is useful for predicting the discharge destination and the value of target rehabilitation. Therefore, the purpose of this study was to calculate cut-off values of ADL independence level based on the number of family caregivers required for home discharge in subacute stroke patients to tailor rehabilitation toward home discharge.

\section{Methodology}

For the present study, we used data from the Rehabilitation Patient Data Bank ("Rehab Patient DB"), which is a large multicenter database under a Health and Labour Sciences Research Grant (2007-2009).

The Rehab Patient DB was created to promote the development of evidence for rehabilitation medicine. It was confirmed that there was no ethical problem in light of the ethical guidelines of epidemiological studies by the Japan Association of Rehabilitation Medicine Data Management Committee.

\section{Subjects}

The subjects comprised 4949 stroke patients (41 hospitals) who were registered in the 2014 version of the Japan Rehabilitation Database (stroke, Kaifukuki rehabilitation wards). This study included 1442 stroke patients (26 hospitals) who met the inclusion criteria and excluded those with missing and abnormal records (Fig. 1). The exclusion criteria were death, changing hospital due to sudden turn for the worse, gastrostomy, and individuals who lived in nursing homes or other residential facilities prior to stroke onset.

\section{Measurement}

The analysis items were as follows.

The subject characteristics included age, sex (male or female), stroke side (right or left, diplegia, or none), stroke type (cerebral infarction, cerebral hemorrhage, or subarachnoid hemorrhage), duration from stroke onset to admission, length of hospital stay, and discharge destination (home or other). Data on the number of caregivers as a nursing force for stroke patients were also collected. The ADL indices were the Barthel index (BI) and the FIM $^{\circledR}$ instrument ${ }^{13)}$ at the time of admission and discharge.

The BI assesses feeding, bathing, grooming, dressing, bowels, bladder, toileting, transfer, mobility, and stairs. Self-care is scored from 0 (complete dependence) to 100 (complete independence) points ${ }^{14}$. The reliability and validity of the BI have been confirmed ${ }^{15,16)}$.

FIM ${ }^{\circledR}$ instrument items are scored using a 7-point scale, where 1 indicates complete dependence, 5 indicates 
Table 1. Subject characteristics

\begin{tabular}{lcccc}
\hline \multirow{2}{*}{ Variable } & $\begin{array}{c}\text { Overall } \\
(\mathrm{n}=1442)\end{array}$ & $\begin{array}{c}\text { No caregiver } \\
(\mathrm{n}=389)\end{array}$ & $\begin{array}{c}\text { One person } \\
(\mathrm{n}=946)\end{array}$ & $\begin{array}{c}\text { Two persons or more } \\
(\mathrm{n}=107)\end{array}$ \\
\cline { 3 - 5 } & $68.7 \pm 13.0$ & $67.8 \pm 12.9$ & $68.7 \pm 12.9$ & $71.2 \pm 14.0$ \\
Age, years & $40.3(581)$ & $43.4(169)$ & $39.2(371)$ & $38.3(41)$ \\
Female, \% (n) & & & & \\
Stroke side & $45.4(654)$ & $47.6(185)$ & $45.0(426)$ & $40.2(43)$ \\
$\quad$ Right-side, \% (n) & $41.5(600)$ & $38.8(151)$ & $42.3(400)$ & $45.8(49)$ \\
Left-side, \% (n) & $4.6(66)$ & $4.9(19)$ & $4.3(41)$ & $5.6(6)$ \\
Diplegia, \% (n) & $8.5(122)$ & $8.7(34)$ & $8.4(79)$ & $8.4(9)$ \\
$\quad$ None, \% (n) & & & & \\
Stroke Type & $61.1(881)$ & $62.7(244)$ & $58.9(557)$ & $74.8(80)$ \\
CI, \% (n) & $31.8(458)$ & $30.9(120)$ & $33.2(314)$ & $22.4(24)$ \\
CH, \% (n) & $7.1(103)$ & $6.4(25)$ & $7.9(75)$ & $2.8(3)$ \\
$\quad$ SH, \% (n) & $38.2 \pm 23.8$ & $35.9 \pm 17.5$ & $39.2 \pm 26.5$ & $37.1 \pm 17.3$ \\
Time post-stroke, days & $103.2 \pm 47.1$ & $99.7 \pm 45.7$ & $103.9 \pm 47.5$ & $109.2 \pm 48.5$ \\
Length of stay, days & $79.9(1152)$ & $67.6(263)$ & $85.6(810)$ & $73.8(79)$ \\
Discharge home, \% (n) & & &
\end{tabular}

$\mathrm{CI}=$ cerebral infarction; $\mathrm{CH}=$ cerebral hemorrhage; $\mathrm{SH}=$ subarachnoid hemorrhage

Table 2. ADL score of each subject

\begin{tabular}{ccccc}
\hline & & \multicolumn{3}{c}{ The number of caregivers } \\
\cline { 3 - 5 } ADL score & $\begin{array}{c}\text { Overall } \\
(\mathrm{n}=1442)\end{array}$ & $\begin{array}{c}\text { No caregiver } \\
(\mathrm{n}=389)\end{array}$ & $\begin{array}{c}\text { One person } \\
(\mathrm{n}=946)\end{array}$ & $\begin{array}{c}\text { Two person or more } \\
(\mathrm{n}=107)\end{array}$ \\
\hline BI & & & & \\
Admission, points & $48.3 \pm 29.6$ & $50.5 \pm 28.9$ & $48.5 \pm 29.4$ & $39.1 \pm 31.9$ \\
$\quad$ Discharge, points & $70.8 \pm 28.1$ & $72.1 \pm 28.0$ & $71.4 \pm 27.1$ & $60.8 \pm 34.2$ \\
FIM $^{\circledR}$ & & & & \\
Admission, points & $72.3 \pm 29.9$ & $75.4 \pm 29.6$ & $72.2 \pm 29.6$ & $61.5 \pm 30.8$ \\
Discharge, points & $93.9 \pm 29.0$ & $97.1 \pm 28.7$ & $94.0 \pm 28.1$ & $81.9 \pm 34.3$ \\
\hline
\end{tabular}

$\mathrm{ADL}=$ Activities of daily living; $\mathrm{BI}=$ Barthel index; $\mathrm{FIM}^{\circledR}=\mathrm{FIM}^{\circledR}$ instrument

supervision, and 7 indicates complete ADL independence ${ }^{17)}$. The reliability and validity of the FIM ${ }^{\circledR}$ instrument have been confirmed in stroke patients ${ }^{18)}$.

\section{Statistical analysis}

Receiver operating characteristic (ROC) curves $^{19)}$ were used to elucidate the BI and FIM ${ }^{\circledR}$ instrument scores necessary for home discharge in stroke patients. Analysis was performed for each subject according to the number of family caregivers, i.e., no caregiver, one person, two persons or more, and overall. Furthermore, cut-off values and their sensitivities and specificities were calculated based on the ROC area under the curve (AUC) and Youden's Index ${ }^{20)}$. SPSS 22.0 statistical software (IBM, Armonk, New York, USA) was used for all statistical analyses. A p-value of < 0.05 was considered statistically significant.

\section{Results}

As shown in Table 1, 1152 patients were discharged home and 290 patients were discharged from hospital to other destinations. Table 2 shows each BI and FIM ${ }^{\circledR}$ instrument scores at the time of admission and discharge. Table 3 shows the cut-off values of ADL scores on discharge for the number of caregivers per subject. The BI cut-off values that discriminated between home discharge and others were $65 / 60$ points (AUC 0.86 , sensitivity $78.4 \%$, specificity $79.0 \%$ ) overall, $75 / 70$ points (AUC 0.86 , sensitivity $82.2 \%$, specificity $82.5 \%$ ) in patients with no caregiver, 65/60 points (AUC 0.87 , sensitivity $79.6 \%$, specificity $81.6 \%$ ) in patients with one caregiver, and $60 / 55$ points (AUC 0.89 , sensitivity $75.9 \%$, specificity $89.3 \%$ ) in patients with two or more caregivers. The FIM ${ }^{\circledR}$ instrument cut-off values were 90/89 points (AUC 0.86 , sensitivity $78.4 \%$, specificity $79.0 \%$ ) overall, $101 / 100$ points (AUC 0.88 , sensitivity $77.9 \%$, specificity $87.3 \%$ ) in patients with no caregiver, 87 / 86 points (AUC 0.88 , sensitivity $78.9 \%$, specificity $82.4 \%$ ) in patients with one caregiver, and 87/86 points (AUC 0.90, sensitivity $73.4 \%$, specificity $96.4 \%$ ) in patients with two or more caregivers. 
Table 3. Cut-off values for the judgment of home discharge by ADL score

\begin{tabular}{ccccc}
\hline \multirow{2}{*}{$\begin{array}{c}\text { ADL score on } \\
\text { discharge }\end{array}$} & $\begin{array}{c}\text { Overall } \\
(\mathrm{n}=1442)\end{array}$ & $\begin{array}{c}\text { No caregiver } \\
(\mathrm{n}=389)\end{array}$ & $\begin{array}{c}\text { One person } \\
(\mathrm{n}=946)\end{array}$ & $\begin{array}{c}\text { Two person or more } \\
(\mathrm{n}=107)\end{array}$ \\
\cline { 3 - 5 } & & & & \\
BI & $0.85(0.82-0.88)$ & $0.86(0.81-0.90)$ & $0.87(0.83-0.90)$ & $0.89(0.82-0.95)$ \\
AUC (95\% CI) & $65 / 60$ & $75 / 70$ & $65 / 60$ & $60 / 55$ \\
Cut-off points, points & 78.4 & 82.2 & 79.6 & 75.9 \\
Sensitivity, \% & 79.0 & 82.5 & 81.6 & 89.3 \\
Specificity, \% & & & & \\
FIM ${ }^{\circledR}$ & $0.86(0.84-0.89)$ & $0.88(0.85-0.92)$ & $0.88(0.85-0.91)$ & $0.90(0.84-0.96)$ \\
AUC (95\% CI) & $90 / 89$ & $101 / 100$ & $87 / 86$ & $87 / 86$ \\
Cut-off points, points & 78.4 & 77.9 & 78.9 & 73.4 \\
Sensitivity, \% & 79.0 & 87.3 & 82.4 & 96.4 \\
Specificity, \% & & &
\end{tabular}

$\mathrm{ADL}=$ Activities of daily living; AUC $=$ Area under the curve; $\mathrm{BI}=$ Barthel index; $\mathrm{FIM}^{\circledR}=\mathrm{FIM}^{\circledR}$ instrument

\section{Discussion}

Subacute rehabilitation unit programs facilitate ADL independence for home discharge. The advisability of home discharge depends not only on ADL independence but also on the power of family care, age of the caregiver, and support frequency ${ }^{21)}$ because nursing for stroke patients is generally conducted by the family members with whom the patient lives ${ }^{22,23)}$. Furthermore, other previous studies have pointed out that the type of discharge is influenced by the presence of a spouse ${ }^{24-26)}$ and social support ${ }^{24-26)}$. Herein, we focused attention on the number of family caregivers because it is easily accessible to rehabilitation staff during hospitalization. To our knowledge, no reports have quantitatively shown the ADL independence level necessary for home discharge according to the number of family caregivers. Therefore, the aim of this study was to score ADL independence level quantitatively according to the number of the family caregivers in subacute stroke patients who received frequent rehabilitation aimed at home discharge.

Our results indicated that the ADL independence level in stroke patients necessary for home discharge was different according to the number of family caregivers, and that home discharge for patients with many caregivers was possible even with low ADL independence levels. These results are in agreement with previous studies ${ }^{10-12)}$, which also reported an association with the number of family caregivers and home discharge. In addition, this present study indicated that there was a large difference in cut-off values depending on the presence or absence of one caregiver.

Furthermore, AUC, sensitivity, and specificity confirmed that the cut-off values in this study had high identification ability. Therefore, these cut-off values are valid and could potentially become a quantitative guide for the independence level necessary for home discharge. This indicator may be useful as a concrete target point for carrying out ADL rehabilitation in stroke patients aimed at home dis- charge. BI and the FIM $^{\circledR}$ instrument are commonly used and have been demonstrated to be reliable and valid ${ }^{3)}$. Therefore, the findings of this study are practical. However, in the future, external validity will need to be examined.

One of the limitations of this study is that we did not address other factors that are considered to be related to the possibility of home discharge (e.g., power of family care, age of the caregiver, and support frequency). The cut-off values of this study had certain accuracy; however, an analysis that's includes those factors may make it possible to create an indicator of higher accuracy. In addition, this study had wide range characteristics of subjects. Stratified analyses of age and stroke severity are needed in future.

\section{Conclusion}

This study calculated the cut-off values of the BI and FIM $^{\circledR}$ instrument for home discharge based on the number of family caregivers in stroke patient. Our results indicated that home discharge for patients with many caregivers was possible even with low ADL independence levels and that there was a large difference in cut-off values depending on the presence or absence of one caregiver. The cut-off values calculated in this study have certain accuracy and may be a useful indicator when the advisability of home discharge was discussed.

\section{Acknowledgments}

This study used the Japan Rehabilitation Database managed by the Japan Association of Rehabilitation Database to whom we express our gratitude. The contents and conclusions of this study are not the opinions of the Association but exclusively those of the authors.

Disclaimer: The use of FIM ${ }^{\circledR}$ instrument to collect data for this research study was authorized and conducted according to the terms of a special purpose license granted by 
the Uniform Data System for Medical Rehabilitation (UDSMR). The licensee has not been trained by the UDSMR in the use of FIM ${ }^{\circledR}$ instrument, and the study's patient data have not been submitted to or processed by the UDSMR. There is no implication that the data have been or will be subjected to the UDSMR's standard data processing procedures or that they are otherwise comparable to data processed by the UDSMR. FIM ${ }^{\circledR}$ is a trademark of UDSMR, a division of UB Foundation Activities, Inc.

\section{References}

1) American Heart Association Statistics Committee and Stroke Statistics Subcommittee: Heart disease and stroke statistics-2015 update: a report from the American Heart Association. Circulation. 2015; 313: e29-322.

2) Statistics and Information Department, Minister's Secretariat, Ministry of Health, Labour and Welfare: Comprehensive survey of living conditions 2007. Available from: http://www.mhlw.go. jp/english/database/db-hss/cslc-tables.html

3) Shinohara Y, Yanagihara T, et al.: VII. Rehabilitation. J Stroke Cerebrovasc Dis. 2011; 20: S145-180.

4) Wilson DB, Houle DH, et al.: Stroke Rehabilitation: A Model Predicting Return Home. West J Med. 1991; 154: 587-590.

5) Teasell RW, Foley NC, et al.: A rehabilitation program for patients recovering from severe stroke. Can J Neurol Sci. 2005; 32: 512-517.

6) Rabadi MH and Blau A: Admission ambulation velocity predicts length of stay and discharge disposition following stroke in an acute rehabilitation hospital. Neurorehabil Neural Repair. 2005; 19: 20-26.

7) Pereira S, Foley N, et al.: Discharge destination of individuals with severe stroke undergoing rehabilitation: a predictive model. Disabil Rehabil. 2014; 36: 727-731.

8) Hamaoka K, Maeda R, et al.: Functional Independence Measure Reference Values for the Discharge to Home of Stroke Patients. Rigakuryoho Kagaku. 2014; 29: 933-937.

9) Sugiura T, Sakurai H, et al.: A Study of ADL Outcome Factors of Elderly Stroke Patients Over 85. Rigakuryoho Kagaku. 2013; 28: 623-626.

10) Niki R: Medico-social Factors which Determine the Discharge Placements of Stroke Patients. Sogo Rehabilitation. 1983; 11: 895-899.

11) Uematsu $M$ and Ikai T: The Conditions for Aged Stroke Patients in order to Discharge to Home Analysis by Classification and Regression Trees (CART). Jpn J Rehabil Med. 2002; 39: 396-
402.

12) Maeshima S, Okamoto $S$, et al.: Potential factors, including activities of daily living, influencing home discharge for patients with putaminal haemorrhage. BMC Neurol. 2016; 16: 1-6.

13) The Date Management Service of the Uniform Date System for Medical Rehabilitation and the Center for functional Assessment Research: Guide for the Uniform Data Set for Medical Rehabilitation, Version 3.0, State University of New York, Buffalo, NY, 1990.

14) Mahoney FI and Barthel DW: Functional Evaluation: The Barthel Index. Md State Med J. 1965; 14: 61-65.

15) Collin C, Wade DT, et al.: The Barthel ADL Index: A Reliability Study. Int Disabil Stud. 1988; 10: 61-63.

16) Laake K, Laake P, et al.: The Barthel ADL Index: Factor Structure Depends Upon the Category of Patient. Age Ageing. 1995; 24: 393-397.

17) Hamilton BB and Granger CV: Disability Outcomes Following Inpatient Rehabilitation for Stroke. Phys Ther. 1994; 74: 494503.

18) Ottenbacher KJ, Hsu Y, et al.: The Reliability of the Functional Independence Measure: A Quantitative Review. Arch Phys Med Rehabil. 1996; 77: 1226-1232.

19) Akoberg AK: Understanding Diagnostic Tests: Receiver Operating Characteristic Curves. Acta Paediatr. 2007; 96: 644-647.

20) Fluss R, Faraggi D, et al.: Estimation of the Youden Index and its Associated Cutoff Point. Biom J. 2005; 47: 458-472.

21) Takahashi T, Ikenaga Y, et al.: Effect of "Familial Care Ability Score" for Predicting Discharge Destination of Stroke Patients. J Clin Rehabil. 2010; 19: 696-699.

22) Anderson CS, Linto J, et al.: A population-based assessment of the impact and burden of caregiving for long-term stroke survivors. Stroke. 1995; 26: 843-849.

23) Cabinet Office, Government of Japan: Annual Report on the Aging Society. 2015, Available from: http://www8.cao.go.jp/koure i/whitepaper/w-2015/zenbun/pdf/1s2s_3_2.pdf

24) Meijer R, van Limbeek J, et al.: Prognostic Social Factors in the Subacute Phase After a Stroke for the Discharge Destination from the Hospital Stroke-unit. A Systematic Review of the Literature. Disabil Rehabil. 2004; 26: 191-197.

25) Mees M, Klein J, et al.: Predicting Discharge Destination after Stroke: A Systematic Review. Clin Neurol Neurosurg. 2016; 142: $15-21$.

26) Everink IH, van Haastregt JC, et al.: Factors Influencing Home Discharge after Inpatient Rehabilitation of Older Patients: A Systematic Review. BMC Geriatr. 2016; 16: 5. 